\title{
A COMPETÊNCIA EM INFORMAÇÃO ALIADA AS TAREFAS DO BIBLIOTECÁRIO ESCOLAR
}

INFORMATION LITERACY FOCUSED ON SCHOOL LIBRARIAN ACTIVITIES

${ }^{1}$ Selma Leticia Capinzaiki Ottonicar

${ }^{1}$ Claudio Marcondes de Castro Filho

${ }^{1}$ Fabiana Sala

\section{Correspondência}

${ }^{1}$ Selma Leticia Capinzaiki Ottonicar

Universidade Estadual Paulista ${ }^{1}$

São Paulo, SP - Brasil.

E-mail: selma.leticia@hotmail.com

Submetido em: 22/02/2018

Aceito em: 26/08/2018

Publicado em: 29/11/2018

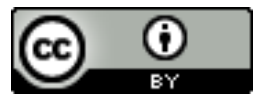

JITA: CE. Literacy 


\section{RESUMO}

A Competência em informação é fundamental para que os indivíduos saibam acessar, avaliar e usar a informação de maneira eficaz ao longo da vida. Consiste em saber utilizar as tecnologias, buscar as informações em vários lugares, interpretar o texto, verificar a fonte de informação e produzir novos conhecimentos. $\mathrm{O}$ objetivo deste estudo é propor a aplicação dos princípios da Competência em informação ao elenco de tarefas dos bibliotecarios escolares. Os procedimentos metodológicos envolvem a pesquisa bibliográfica no âmbito da Competência em informação e das políticas públicas voltadas ao contexto das bibliotecas escolares. Para tanto, buscou-se em livros e artigos impressos e digitais em diferentes periódicos da área da ciência da informação. Como considerações finais, defende-se que a Competência em informação precisa ser considerada pelas políticas públicas da biblioteca escolar no Brasil, a fim de que se torne subsídio à prática do bibliotecário escolar e melhore o serviço oferecido pelas bibliotecas.

\section{PALAVRAS-CHAVE}

Políticas públicas. Competência em informação. Biblioteca escolar. Aprendizagem ao longo da vida. Desenvolvimento de saberes.

\section{ABSTRACT}

Information literacy is important to access, evaluate and use information in an efficient way. Furthermore, information literacy helps individuals to use technology, to seek information, to interpret a text, to verify an information source and to produce new knowledge. This paper aims to discuss how information literacy contributes to the development of public policy for school libraries. The public policy should focus on librarians' lifelong learning. The methodological procedures involve a bibliographical research about information literacy and public policy in the context of school libraries. Therefore, we researched materials like books, printed and digital articles in many journals in the information science field. In conclusion, we illustrated that information literacy needs to be considered in public policy of school libraries in Brazil, so that this literacy can guide information professionals and improve the services offered by the libraries.

\section{KEYWORDS}

Public policy. Information literacy. School library. Lifelong learning. Knowledge development. 


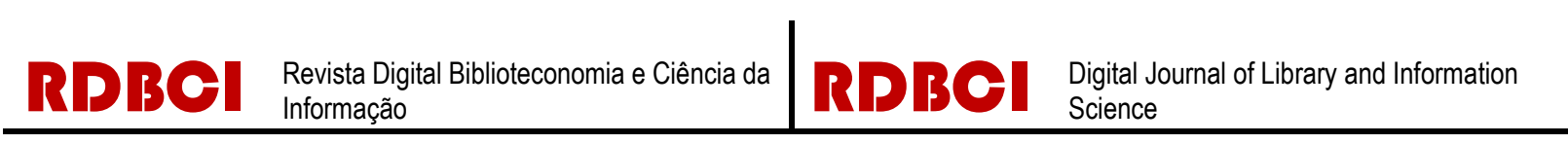

\section{INTRODUÇÃO}

Atualmente a sociedade vive em um contexto de transformação de tecnologias da informação e comunicação (TIC) muito ágil. A internet, os computadores e celulares permitem que as informações sejam disseminadas de maneira veloz em diversos âmbitos como o econômico, o social e o político. Nesse contexto, os indivíduos necessitam se capacitar, saber como buscar e avaliar a informação em um universo repleto de fontes de informações. Aqueles que sabem como realizar o acesso, a avaliação e o uso das informações são considerados como competentes em informação.

Ser competente em informação não significa apenas utilizar as TIC para alcançar seus objetivos, mas também interpretar as informações com base no contexto em que se está envolvido e na ideologia constituinte às fontes de informação. Para Belluzzo e Feres (2015), esta competência é fundamental para realizar o aprendizado ao longo da vida em âmbito pessoal, profissional e social.

A Competência em informação ${ }^{1}$ é assunto recorrente em pesquisas na área da Ciência da Informação e surgiu em 1974 por meio do discurso de Paul Zurkowski nos Estados Unidos. A partir de então, vários pesquisadores da área se empenharam no desenvolvimento desta competência em diversos países.

O esforço dos pesquisadores também se volta à disseminação do tema para a comunidade científica e a sociedade em geral, devido à necessidade do estabelecimento de políticas que promovam a Competência em informação nas diversas instituições como escolas, bibliotecas, empresas e demais organizações.

As políticas públicas são os principais instrumentos de implementação de uma ideia, pois são instituídas por meio da hierarquia social. O governo demonstra valorizar aquele tema e fornece recursos para que as demais organizações possam utilizá-lo de maneira prática.

O Brasil tem enfrentado dificuldades para disseminar temas e conceitos da área da Ciência da Informação nas políticas públicas do país. Em 2003 surgiu uma preocupação inicial no âmbito da leitura e da biblioteca escolar, disseminada pela implementação da Lei n. 10.753 de 2003 que instituiu a política Nacional do Livro. Percebe-se que a valorização da aprendizagem ao longo da vida se inicia devido à necessidade de estimular a leitura nos brasileiros.

\footnotetext{
${ }^{1}$ Também conhecida como competência em informação
} 


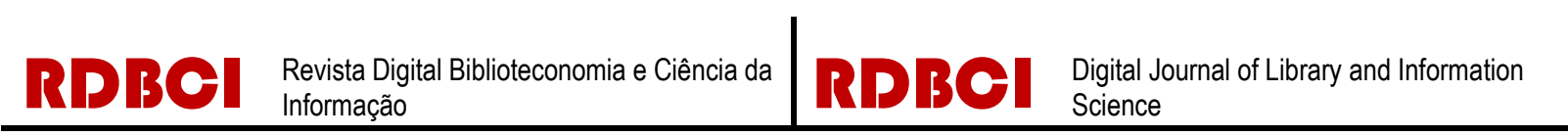

Além de valorizar as bibliotecas e o bibliotecário escolar como fatores fundamentais para o estímulo ao conhecimento, há a necessidade de se valorizar o aprendizado, que se constitui como Competência em informação, para o exercício da cidadania.

Desse modo o presente artigo apresenta como problema de pesquisa a seguinte questão: Como é possível correlacionar as atividades do bibliotecário escolar com os padrões e indicadores da Competência em informação? Para tanto, o objetivo geral consiste em elaborar um quadro relacional das atividades do bibliotecário escolar com os padrões indicadores pelo quadro conceitual desta competência.

Acredita-se que essa temática é fundamental para a construção do arcabouço teórico no âmbito da Competência em informação, uma vez que, considera esta competência no contexto das políticas públicas da biblioteca escolar. O estudo da Competência em informação no contexto das políticas públicas ainda é considerado um tema novo e pouco explorado pela área, sendo assim o trabalho pode ser tomado como um primeiro passo para a análise das relações interdisciplinares inerentes à complexidade do tema.

\section{PROCEDIMENTOS METOdológicos}

A presente pesquisa é de natureza exploratória de caráter qualitativo, pois realizou-se pesquisa bibliográfica a respeito dos temas Competência em informação e políticas públicas voltadas ao contexto das bibliotecas escolares. Para tanto, buscou-se em livros e artigos digitais de periódicos da área da Ciência da Informação.

Utilizaram-se as seguintes palavras chave: políticas públicas, Competência em informação, biblioteca escolar, aprendizagem ao longo da vida e desenvolvimento de saberes. Tais palavras se adéquam ao objetivo proposto e contribuíram para a evolução da discussão proposta pelo artigo. A pesquisa foi realizada no portal de periódicos da Coordenação de Aperfeiçoamento de Pessoal de Nível Superior (CAPES) e na Base de Dados Referenciais de Artigos de Periódicos em Ciência da Informação (BRAPCI).

O período desenvolvido da pesquisa nas bases de dados ocorreu entre maio e agosto de 2018. Os autores utilizados foram Dudziak, Ferreira e Ferrari (2017), Belluzzo (2017), Belluzzo, Kobayashi e Feres (2004), Castro Filho (2016), Campelo (2003), Belluzzo (2007), Vitorino (2006), Castro Filho e Campos (2014). Além dos autores, utilizaram-se documentos internacionais e legais sobre a temática da Competência em informação e da biblioteca escolar da IFLA e UNESCO (2015), Declaração de Maceió (2011), Manifesto de Florianópolis (2013), Carta de Marília (2014) e as leis do Brasil (1997; 2003; 2014, 2018) e São Paulo (1986). 


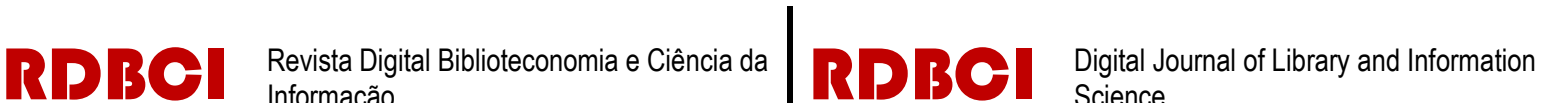

A pesquisa bibliográfica converge com o objetivo, uma vez que está centrada na reflexão sobre a forma com que a Competência em informação contribui para a elaboração de políticas públicas da biblioteca voltadas ao aprendizado ao longo da vida. A pesquisa bibliográfica é também pertinente para lidar com questões novas da área que ainda não foram tema de cunho prático, e por isso foi escolhida como metodologia empregada neste artigo.

\section{LEIS E POLíticAS PÚBLICAS DA BIBLIOTECA ESCOLAR}

De modo geral, as políticas públicas são ações realizadas pelo Estado a fim de que sejam implementadas pelas instituições. Tais políticas agem diretamente na vida do cidadão e têm por objetivo melhorar a qualidade de vida da população ou de uma determinada comunidade.

Para Crispino (2016), o conceito de políticas públicas é muito amplo, pois varia dependendo do autor. Assim, o conceito de política pública:

[...] é resultado de inúmeras variáveis (constructo) e que seu significado será tão distinto quanto os valores, ideologias, contextos, éticas e etc. de seu formulador. Em outras palavras, o conceito de políticas públicas não surge por si mesmo ou por fatores endógenos exclusivos. Ele é delimitado pelas múltiplas possibilidades de conexão de ações que contribuem para fazer dela, a política pública, o centro de equilíbrio dessas forças sociais diferentes.

Com base nas afirmações de Crispino (2016), as políticas públicas são o centro das ações e suas interconexões. Tais ações são influenciadas no contexto de vida do indivíduo que as criam. Assim, o autor propõe a construção do conceito por meio da divisão das palavras que o compõem: política e pública.

\footnotetext{
Como política, vamos entender a arte de governar ou de decidir os conflitos que caracterizam os agrupamentos sociais. Como pública vamos entender aquilo que pertence a um povo, algo relativo às coletividades. Logo, poderemos deduzir que política pública - em um metaconceito - seria ação intencional de governo que vise atender à necessidade da coletividade. A este metaconceito simplificante iremos agregar variáveis, instituir valores, perceber arranjos de forças, identificar processos e metas, propor avaliações (CRISPINO, 2016, p. 19).
}

As políticas públicas envolvem ações voltadas para as comunidades com base em uma intenção predefinida. A intencionalidade também faz parte do conceito de política pública, à medida que: "a política pública é a intencionalidade de ação de governo" (CRISPINO, 2016, p. 22). A intencionalidade possibilita avaliar o fenômeno de dois modos diferentes, conhecidos como criação política e ação governamental (CRISPINO, 2016).

A ação política está relacionada com certas regras políticas, já as leis ocorrem por meio dos instrumentos legais, ou seja, deve se submeter às normas do direito (CRISPINO, 2016). É a implementação prática seguida da etapa de criação política para que o povo usufrua das ações planejadas e melhorem sua qualidade de vida. 


\section{RDBCI

No Brasil existem inúmeras dificuldades que complicam a implementação das políticas públicas devido à história da política no país. Tais problemas estão relacionados com a corrupção, que gera o ganho de recursos financeiros ilícitos e poder (CRISPINO, 2016).

Diante desse complexo cenário político, existem diversas políticas públicas estabelecidas com a finalidade de valorizar a leitura, o livro e a biblioteca escolar no Brasil. Tais políticas começaram a ter maior visibilidade a partir de 1997 com a criação do "Programa Nacional de Biblioteca" e continuam a ser desenvolvidas até os dias atuais. Dentre as principais iniciativas do governo federal no âmbito do livro, leitura e biblioteca escolar, merecem destaque:

- Programa Nacional de Biblioteca desenvolvido por meio da Portaria Ministerial n. 584/1997;

- Lei n. 10.753/2003, que dispõe sobre a Política Nacional do Livro;

- Lei n. 12.244/2010, que institui as Bibliotecas Escolares;

- A Lei n. 13.005/2014, que aprova o Plano Nacional de Educação (2014-2024);

- Plano Nacional do Livro e Leitura, publicado por meio do Decreto n. 7.559/2011;

- Lei 13.696/2018, que institui a Política Nacional de Leitura e Escrita.

Cada uma dessas leis compõem um estímulo à leitura e à valorização das bibliotecas públicas e escolares como organizações importantes para o desenvolvimento das pessoas. Os cidadãos necessitam desenvolver suas capacidades, habilidades e experiências para que aprendam cada vez mais e sejam competentes para transformar informação em conhecimento. As leis são explicadas conforme o quadro 1 :

Quadro 1. Leis e políticas públicas que contribuem com as bibliotecas escolares.

\begin{tabular}{|l|l|l|}
\hline Política Pública & Data da criação & Descrição \\
\hline Programa Nacional de & 1997 & $\begin{array}{l}\text { Dentre os objetivos tem-se o suporte e a difusão de } \\
\text { Brogramas que são destinados a promover o hábito de } \\
\text { leitura, além da produção/difusão de materiais } \\
\text { designados ao apoio de projetos de } \\
\text { capacitação/atualização dos professores no ensino } \\
\text { fundamental" (BRASIL, 1997, p. 8519). }\end{array}$ \\
\hline $\begin{array}{l}\text { Lei n. 10.753 sobre a } \\
\text { Política Nacional do }\end{array}$ & 2003 & $\begin{array}{l}\text { Garantir ao indivíduo o direito de acesso ao livro, de } \\
\text { promover e incentivar o hábito da leitura, de qualificar a } \\
\text { população para a utilização do livro e principalmente de } \\
\text { instalar e ampliar no país livrarias e bibliotecas } \\
\text { (BRASIL, 2003, p1). }\end{array}$ \\
\hline $\begin{array}{l}\text { Lei n. 13.005 Plano } \\
\text { Nacional de Educação }\end{array}$ & $2014-2024)$ & $\begin{array}{l}\text { Tem como missão, no item 7.20: "Prover equipamentos e } \\
\text { recursos tecnológicos digitais para a utilização } \\
\text { pedagógica no ambiente escolar a todas as escolas } \\
\text { públicas da educação básica, criando, inclusive, } \\
\text { mecanismos para implementação das condições } \\
\text { necessárias para a universalização das bibliotecas nas } \\
\text { instituições educacionais, com acesso a redes digitais de } \\
\text { computadores, inclusive a internet". (BRASIL, 2014). }\end{array}$ \\
\hline Lei n. 12.244 & & "Dispõe sobre a universalização das bibliotecas nas \\
\hline
\end{tabular}

v.17

$1-23$
e019005 


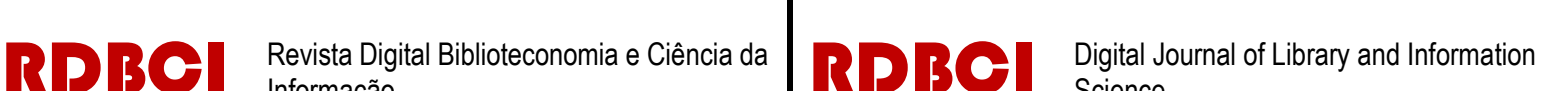 Informação

\begin{tabular}{|l|l|l|}
\hline & & instituições de ensino do País" (BRASIL, 2010). \\
\hline $\begin{array}{l}\text { Plano Nacional do } \\
\text { Livro e Leitura }\end{array}$ & 2011 & $\begin{array}{l}\text { O PNLL é composto por quatro Eixos, sendo: 1) } \\
\text { "democratização do acesso"; 2) "fomento à leitura e à } \\
\text { formação de mediadores"; 3) "valorização da leitura e } \\
\text { comunicação"; e 4) "desenvolvimento da economia do } \\
\text { livro" (BRASIL, 2006, p. 26). }\end{array}$ \\
\hline $\begin{array}{l}\text { Lei n. 13.696 que } \\
\text { institui a Política } \\
\text { Nacional de Leitura e } \\
\text { Escrita }\end{array}$ & $\begin{array}{l}\text { "Fica instituída a Política Nacional de Leitura e Escrita } \\
\text { como estratégia permanente para promover o livro, a } \\
\text { leitura, a escrita, a literatura e as bibliotecas de acesso } \\
\text { público no Brasil. } \\
\text { Parágrafo único. A Política Nacional de Leitura e } \\
\text { Escrita será implementada pela União, por intermédio do } \\
\text { Ministério da Cultura e do Ministério da Educação, em } \\
\text { cooperação com os Estados, o Distrito Federal e os } \\
\text { Municípios e com a participação da sociedade civil e de } \\
\text { instituições privadas" (BRASIL, 2018). }\end{array}$ \\
& \\
\hline & \\
\hline
\end{tabular}

(1986)].

Fonte: [os autores com base em Castro Filho (2016), Brasil (1997; 2003; 2014; 2018) e São Paulo

O projeto de Lei do Senado 212, criado em 2016 e aprovado em 2017, é considerado um marco histórico ao afirmar que a leitura impacta de maneira positiva a qualidade da vida cidadã:

[...] os impactos positivos e duradouros da leitura e da escrita são encontrados em praticamente todas as dimensões relevantes da vida individual e coletiva. Com leitura são formados cidadãos mais críticos, autônomos e mais bem qualificados; são construídas organizações e instituições - públicas ou privadas e do terceiro setor - mais eficientes, eficazes, inovadoras e responsáveis; enfim, consolidam-se comunidades, bairros, cidades e sociedades mais justas, solidárias e autônomas. Neste sentido, o letramento pleno, a leitura e a escrita, estão inescapavelmente no centro da agenda do desenvolvimento das nações, especialmente no Brasil em sua acertada luta contra as desigualdades. A leitura é a chave mestra para a mobilidade social e o desenvolvimento pleno. Um país sem miséria, uma Pátria Educadora, se afirma com uma política pública de leitura plena, mobilizadora, inclusiva, que possibilita a democratização das oportunidades de modo duradouro em nosso país. A leitura e a escrita, assim proclamam os militantes do livro, da leitura, da literatura e das bibliotecas, é a chave de todos os direitos humanos na sociedade contemporânea, reconhecida como a da informação e conhecimento (BRASIL, 2016, p. 4, grifo nosso).

Elementos que compõem a Competência em informação fazem parte da descrição da Lei 212/2017 grifadas acima na citação, ao contribuírem para que os indivíduos sejam críticos e as organizações eficazes de modo a atingirem seus objetivos e tornarem as comunidades justas e solidárias. Esta lei é vista como fator-chave para o exercício dos direitos humanos na sociedade da informação e do conhecimento no Brasil.

Além dessa iniciativa, há também o projeto de lei no 28 de 2015 que institui a Política Nacional de Bibliotecas que, ao ser aprovado, pretende contribuir de forma significativa à promoção da

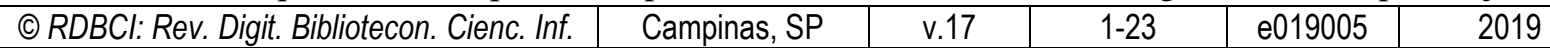




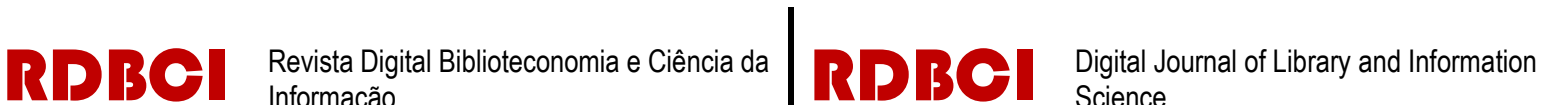

Competência em informação nas discussões e compartilhamento de experiências e práticas no âmbito das bibliotecas e sua articulação com a formação integral dos indivíduos, conforme indica no artigo 26:

\author{
É facultado às bibliotecas: \\ I - promover ações educativas e culturais, fundamentadas no respeito à diversidade \\ cultural e na participação comunitária, destinadas a contribuir para a ampliação da \\ competência em informação, de maneira a garantir o acesso da sociedade ao \\ conhecimento produzido (BRASIL, 2015, p. 7, grifo nosso).
}

Nesse sentido, a Competência em informação contribui para que os indivíduos tenham maior criticidade diante das diferentes situações da vida pessoal, profissional e social. A Competência em informação ocorre não apenas pela leitura de textos escritos, mas pela leitura de mundo das pessoas.

\section{COMPETÊNCIA EM INFORMAÇÃO}

A competência em informação é um tema relativamente novo na Ciência da Informação, pois surgiu em 1974 com Paul Zurkowski. A partir de então, o tema vem ganhando destaque internacional e há uma luta por parte dos pesquisadores e das organizações internacionais em disseminar sua importância para a sociedade em geral.

\section{A United Nations Educational, Scientific, Cultural Organization (UNESCO) tem} realizado diversos manifestos em várias línguas para divulgar a importância da Competência em informação na construção do pensamento crítico dos indivíduos. Tais manifestos também são divulgados como resultados de congressos nacionais e internacionais ao redor do mundo, de modo a demonstrar como os pesquisadores daquele país compreendem o tema.

No Brasil, os principais documentos que focam a Competência em informação são: a Declaração de Maceió, o Manifesto de Florianópolis e a Carta de Marília. A Declaração de Maceió (2011) foi o resultado do XXIV Congresso Brasileiro de Biblioteconomia, Documentação e Ciência da Informação (CBBD) realizado em Maceió, Estado de Alagoas. No âmbito do Congresso, houve outro evento, o "Seminário sobre Competência em informação", que desenvolveu e divulgou o documento (DUDZIAK; FERREIRA; FERRARI, 2017).

A declaração apontou que os recursos tecnológicos que a sociedade possui para acessar a informação não são suficientes para atender as necessidades da cidadania. Por isso, a formação com base da Competência em informação é fundamental para o desenvolvimento dos indivíduos (DECLARAÇÃO, 2011).

O Manifesto de Florianópolis (2013) surgiu como resultado do II Seminário "Competência em Informação: Cenários e Tendências". Esse seminário também ocorreu

\begin{tabular}{l} 
(c) RDBCl: Rev. Digit. Bibliotecon. Cienc. Inf. \\
\hline
\end{tabular}




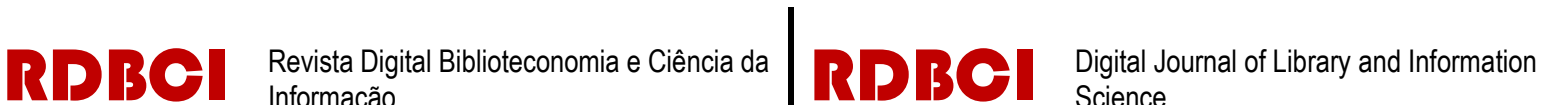

junto com o Congresso Brasileiro de Biblioteconomia, Documentação e Ciência da Informação (CBBD) e já enfatizava o papel das bibliotecas e dos bibliotecários. O documento demonstrou que a Competência em informação é "intrínseca ao próprio ser", pois contribui com a sobrevivência e cidadania das pessoas (DUDZIAK; FERREIRA; FERRARI, 2017).

O Manifesto apontou a importância da mobilização do governo rumo a esta competência:

\begin{abstract}
Nós, bibliotecários e profissionais de áreas afins, acreditamos que a Competência em informação é um fator crítico e condicionante ao desenvolvimento social, cultural e econômico do Brasil na contemporaneidade e, portanto, merece a atenção primária no que tange à mobilização da Sociedade Civil organizada e dos Órgãos Governamentais para a sua integração às ações de democracia e exercício pleno da cidadania (MANIFESTO, 2013, p.1).
\end{abstract}

A Carta de Marília (2014) surgiu a partir do "III Seminário de Competência em Informação: Cenários e Tendências", e propôs a adoção da abreviatura CoInfo para o termo 'Competência em informação' na cidade de Marília, Estado de São Paulo. Dentre as recomendações do documento, destaca-se:

\begin{abstract}
O exercício da democracia e dos direitos humanos reforçam as oportunidades em termos da redução das iniquidades sociais e das desigualdades regionais no contexto brasileiro. Entretanto, este cenário depende da existência de políticas públicas que favoreçam a sua ampliação e a consolidação de avanços alcançados em diferentes áreas, em especial àquela que diz respeito à competência em informação, cujo enfoque está dirigido à dimensão humana e tecnológica para a construção de conhecimento na sociedade contemporânea (CARTA, 2014, p. 1, grifo nosso).
\end{abstract}

Nesse sentido, a Competência em informação necessita do Estado para que crie políticas públicas voltadas ao desenvolvimento do pensamento crítico dos cidadãos. $\mathrm{O}$ exercício da cidadania exige a avaliação das fontes de informação, ou seja, compreender os interesses que acompanham a disseminação da informação pelos veículos de comunicação.

Complementando, Belluzzo (2017, p. 47) afirma: “[...] esse tema tem sido bastante pesquisado e divulgado nos países desenvolvidos, sendo que no nosso contexto essas iniciativas têm ocorrido em pouca escala [...]". Sendo assim, há uma demanda em implementar políticas públicas que forneçam condições aos brasileiros para realizar o aprendizado ao longo da vida e avaliar as informações que recebem.

Além disso, o documento acrescenta:

A aprendizagem, em seus vários níveis, exige o desenvolvimento da Competência em Informação. Destaca-se a importância do trabalho integrado e colaborativo para a transformação das redes, sistemas, unidades e serviços de informação, tais como:

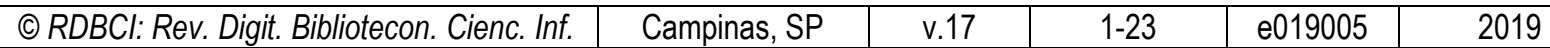




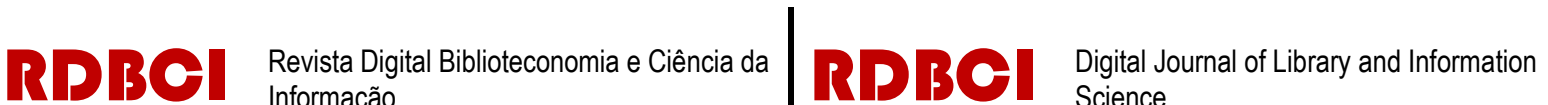

bibliotecas, arquivos, museus, centros de documentação/informação, além de outros tipos de organizações que atuam com informação e conhecimento, cujos espaços de atenção primária voltam-se às necessidades de exercício da cidadania e do aprendizado ao longo da vida (CARTA, 2014, p. 1).

As bibliotecas têm papel central nesse contexto à medida que contribuem com a construção de conhecimento dos indivíduos e apoiam as organizações escolares para atingirem seus objetivos. O aprendizado ao longo da vida é o objetivo principal da Competência em informação, pois acontece nos mais diversos aspectos da experiência humana, pessoal, profissional e social.

\section{Belluzzo, Kobayashi e Feres (2004, p. 87) concordam que a Competência em informação:}

inegavelmente, está ligada ao aprendizado e à capacidade de criar significado a partir da informação, sendo uma condição que as pessoas saibam "aprender a aprender" e realizem o aprendizado ao longo da vida".

Complementando Belluzo, Kobayashi e Feres (2004), Demasson, Partridge e Bruce (2016), baseados na abordagem relacional, acrescentam que:

\begin{abstract}
a Competência em informação fornece os meios pelos quais a experiência da pessoa com a informação (o modo como eles localizam, avaliam e geram informação) pode ser examinada e entendida. É uma lente que possibilita os pesquisadores examinar as experiências de informação das pessoas como também o lazer proporciona uma lente para observar as experiências dos indivíduos com o lazer (DEMASSON; PARTRIDGE; BRUCE, 2016, p. 3, tradução nossa).
\end{abstract}

Assim, a Competência em informação envolve vários elementos como o cognitivo, o comportamento e as experiências das pessoas em qualquer aspecto da vida. Ela pode ser adquirida tanto pela vivência quanto pela aprendizagem nas organizações tradicionais de ensino. Os indivíduos aprendem em grupo ou individualmente por meio do acesso, da avaliação e do uso da informação, transformando-a em conhecimento.

Dentre as organizações que podem se utilizar da Competência em informação, destacase a biblioteca escolar, que tem como papel contribuir para que os discentes desenvolvam capacidades e habilidades para se tornarem cidadãos. Para Campello (2003), esta competência foi o principal fator de integração da biblioteca com o currículo escolar. Castro Filho (2016, p. 31) corrobora as ideias de Campello (2003) ao mencionar que:

nesse aspecto, a biblioteca escolar deve ser reconhecida como um equipamento cultural e, ainda, como uma instituição social, com o intuito de integrar a sociedade da informação, estabelecendo novos conceitos, e se adequando as realidades sociais, culturais, educativas, tecnológicas da sociedade. Com a explosão informacional, a sociedade contemporânea necessita de profissionais bibliotecários que atuem em

\begin{tabular}{l|l|l|l|l|l|}
\hline (c) RDBCl: Rev. Digit. Bibliotecon. Cienc. Inf. & Campinas, SP & v.17 & $1-23$ & e019005 & 2019 \\
\hline
\end{tabular}




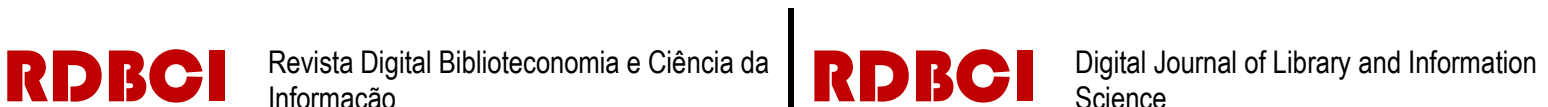

biblioteca escolar com competências que possam atender as novas demandas de produtos e serviços de informação.

As bibliotecas escolares demandam inúmeras ações e posições dos profissionais da informação. A organização e a classificação de documentos já não são mais as únicas atividades deste profissional. Por isso, deve-se valorizar a colaboração com outras bibliotecas, incentivar na cultura organizacional o compartilhamento do conhecimento, o trabalho em grupo e se utilizar da gestão do conhecimento (CASTRO FILHO, 2016).

Nesse contexto, há a necessidade de se avaliar o profissional da informação por meio de sua formação. É fundamental investigar se os discentes de biblioteconomia aprendem a atuar nas bibliotecas escolares com base nas políticas públicas e competências. Defende-se que tanto as competências quanto as políticas públicas são importantes para realizar as atividades educativas e culturais (CASTRO FILHO, 2016).

\section{RESULTADOS E DISCUSSÕES}

A UNESCO, em parceria com a IFLA em 2015, compartilhou o Manifesto sobre a biblioteca escolar. Esse documento trata da função da biblioteca escolar voltada à aprendizagem para todos. De acordo com a UNESCO e a IFLA (2015, sem paginação, tradução nossa), esta biblioteca:

[...] proporciona informação e ideias que são fundamentais para se desenvolver com êxito em nossa sociedade contemporânea, baseada na informação e no conhecimento. Proporciona aos alunos competências para a aprendizagem ao longo da vida e contribui com o desenvolvimento da imaginação, permitindo-lhes que conduzam na vida como cidadãos responsáveis.

A biblioteca escolar contribui com a aprendizagem dos discentes por fazer parte do processo educativo. Seus objetivos envolvem questões sobre o ensino, a cultura, os conhecimentos básicos e a informação (UNESCO; IFLA, 2015). Sendo assim, ambas organizações internacionais sugerem oito objetivos:

- Respaldar e realizar os objetivos do projeto educativo do centro escolar e do plano de estudos;

- Estimular e fomentar nas crianças o hábito e o prazer da leitura, a aprendizagem e a utilização das bibliotecas ao longo da vida;

- Oferecer oportunidades para realizar experiências de criação e utilização da informação a fim de adquirir conhecimentos; compreender, desenvolver a imaginação e se entreter; 


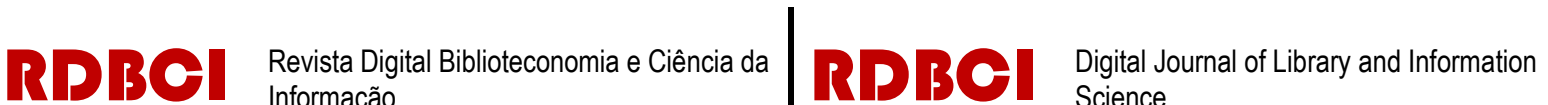

- Apoiar alunos na aquisição/aplicação de capacidades que os permitam avaliar/utilizar a informação, independentemente do suporte/formato ou meio de difusão, tendo em conta a sensibilidade com as formas de comunicação existentes na comunidade;

- Facilitar o acesso aos recursos e possibilidades locais, regionais, locais e mundiais para que os alunos tenham contato com ideias, experiências e várias opiniões;

- Organizar atividades que estimulem a conscientização e a sensibilização nos planos social e cultural;

- Trabalhar com os alunos, professores, administração e as famílias para realizar o projeto educativo do centro escolar; divulgar a ideia de que a liberdade intelectual e o acesso a informação são fundamentais para realizar o projeto educativo do centro escolar;

- Incentivar a leitura e promover os recursos e serviços da biblioteca escolar dentro e fora do conjunto da comunidade escolar.

É necessário desenvolver políticas institucionais e serviços que atendam aos objetivos propostos, bem como comprar os materiais, facilitar o acesso aos materiais intelectuais e também as fontes de informação. Não obstante, deve disponibilizar os recursos didáticos e empregar profissional capacitado (UNESCO, IFLA, 2015).

Em relação ao papel do bibliotecário escolar, é fundamental que esteja:

[...] envolvido na programação para o desenvolvimento curricular, em colaboração com os gestores da escola, os administradores e os professores. Ele tem o conhecimento e as competências relacionados com o fornecimento da informação e a resolução de problemas de informação, bem como a perícia na utilização de todas as fontes, impressas e eletrônicas. O seu conhecimento, as suas competências e a sua perícia vão ao encontro das necessidades de uma comunidade escolar específica. Para lá disso, ele deve conduzir campanhas de leitura e a promoção da literatura, dos media e da cultura para crianças (VITORINO, 2006, p. 12).

Assim, os docentes, os profissionais da informação e os gestores trabalham juntos para desenvolver um currículo que atenda aos objetivos educacionais. Os usuários necessitam acessar, avaliar e usar a informação e suas fontes para solucionar suas dúvidas e aprender algo novo.

O bibliotecário escolar tem vários deveres para garantir a eficácia da biblioteca na participação da educação. Portanto, espera-se que o profissional:

- analise os recursos e as necessidades de informação da comunidade escolar

- formule e promova políticas para o desenvolvimento dos serviços

- desenvolva políticas e sistemas de aquisição para os recursos da biblioteca

- catalogue e classifique documentos e recurso em geral 


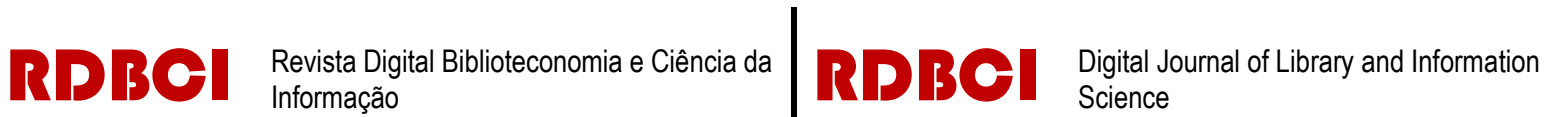

- forme para a utilização da biblioteca

- forme nas competências de literacia da informação e de conhecimento da informação

- apoie alunos e professores na utilização de recursos da biblioteca e de tecnologia da informação

- dê resposta a pedidos de referência e de informação utilizando os materiais adequados

- promova programas de leitura e eventos culturais

- participe em atividades de planificação relacionadas com a gestão do currículo

- participe na preparação, promoção e avaliação de atividades de aprendizagem.

- promova a avaliação de serviços de biblioteca enquanto componente normal e regular do sistema de avaliação global da escola

- construa parcerias com organizações externas

- prepare e aplique orçamentos • conceba planejamento estratégico

- faça a gestão e a formação da equipa da biblioteca (VITORINO, 2006, p. 13).

A fim de elaborar o planejamento destas bibliotecas, o bibliotecário escolar também precisa ser competente em informação. Esta competência é fundamental para o desenvolvimento das sugestões determinadas pela IFLA e pela UNESCO.

A Competência em informação apresenta padrões e indicadores que podem nortear a atuação do bibliotecário escolar de modo a cumprir os requisitos necessários para o desenvolvimento de suas atividades propostas pela UNESCO e IFLA (2015). Os padrões são disseminados internacionalmente por diversos países e no caso do Brasil, a autora Belluzzo (2007) tem traduzido e adaptado ao contexto nacional, conforme o Quadro 2.

Quadro 2. Padrões, indicadores e resultados desejáveis de Competência em informação

\begin{tabular}{|c|l|}
\hline Padrões & Indicadores e resultados desejáveis de Competência em informação \\
\hline $\mathbf{1}$ & $\begin{array}{l}\text { A pessoa "competente em informação" define a natureza e a extensão da sua } \\
\text { necessidade de informação. }\end{array}$ \\
\hline $\mathbf{2}$ & A pessoa "competente em informação" acessa a informação de forma precisa. \\
\hline $\mathbf{3}$ & $\begin{array}{l}\text { A pessoa "competente em informação" avalia a informação e suas fontes de forma } \\
\text { crítica. }\end{array}$ \\
\hline $\mathbf{4}$ & $\begin{array}{l}\text { A pessoa "competente em informação" utiliza a informação com efetividade a fim } \\
\text { de alcançar um objetivo/resultado. }\end{array}$ \\
\hline $\mathbf{5}$ & $\begin{array}{l}\text { A pessoa "competente em informação" compreende as questões (econômicas, legais } \\
\text { e sociais) que envolvem o uso da informação, acessa e utiliza essa informação de } \\
\text { forma ética e legal. }\end{array}$ \\
\hline
\end{tabular}

Fonte: [BELUZZO, 2007] 


\section{RDBCI

Assim, propõe-se o Quadro 3 de inter-relação entre os padrões, indicadores e resultados desejáveis de Competência em informação com as atividades principais do bibliotecário escolar, conforme segue.

Quadro 3. Atividades do bibliotecário escolar, padrões e indicadores da Competência em informação

\begin{tabular}{|c|c|c|}
\hline $\begin{array}{c}\text { Padrões e indicadores da } \\
\text { Competência em informação } \\
\text { (que se desejam formar no } \\
\text { usuário) }\end{array}$ & $\begin{array}{c}\text { Atividades do } \\
\text { bibliotecário escolar }\end{array}$ & $\begin{array}{c}\text { Atitudes, habilidades e competências do } \\
\text { bibliotecário }\end{array}$ \\
\hline $\begin{array}{l}\text { Padrão } 1 \text { - A pessoa "competente } \\
\text { em informação" define a natureza } \\
\text { e a extensão da sua necessidade } \\
\text { de informação. }\end{array}$ & $\begin{array}{l}\text { Analisa os recursos e } \\
\text { as necessidades de } \\
\text { informação } \text { da } \\
\text { comunidade escolar }\end{array}$ & $\begin{array}{l}\text { Precisa conhecer a necessidade informacional } \\
\text { dos usuários. Estar em contato com os alunos e } \\
\text { participar das aulas, palestras e eventos da } \\
\text { escola. Além disso, deve conhecer a } \\
\text { necessidade de informação dos professores e da } \\
\text { gestão escolar. Fazer parcerias com os demais } \\
\text { membros da organização e participar da } \\
\text { reuniões e desenvolvimento dos currículos. }\end{array}$ \\
\hline $\begin{array}{l}\text { Padrão } 2 \text { - A pessoa "competente } \\
\text { em informação" acessa a } \\
\text { informação de forma precisa. }\end{array}$ & $\begin{array}{l}\text { Formula e promove } \\
\text { políticas para o } \\
\text { desenvolvimento dos } \\
\text { serviços }\end{array}$ & $\begin{array}{l}\text { Para promover uma política de } \\
\text { desenvolvimento dos serviços é importante que } \\
\text { saiba acessar a informação sobre as políticas } \\
\text { sugeridas para a biblioteca escolar e aos } \\
\text { serviços da organização. }\end{array}$ \\
\hline $\begin{array}{l}\text { Padrão } 3-\text { A pessoa "competente } \\
\text { em informação" avalia a } \\
\text { informação e suas fontes de forma } \\
\text { crítica. }\end{array}$ & $\begin{array}{l}\text { Desenvolve políticas } \\
\text { e sistemas de } \\
\text { aquisição para os } \\
\text { recursos da biblioteca }\end{array}$ & $\begin{array}{l}\text { Precisa conhecer como os usuários podem } \\
\text { acessar os recursos da biblioteca, se devem } \\
\text { conhecer como manusear as tecnologias de } \\
\text { informação e comunicação, ou como } \\
\text { emprestam os livros, vídeos, revistas e assim } \\
\text { desenvolver uma política institucional segundo } \\
\text { os recursos e às necessidades dos usuários. }\end{array}$ \\
\hline $\begin{array}{l}\text { Indicador } 3.2 \text { Articula e aplica } \\
\text { critérios de avaliação para a } \\
\text { informação e as fontes. } \\
3.2 .3 \text { Reconhece e descreve os } \\
\text { vários aspectos de uma fonte, seus } \\
\text { impactos e valor para o projeto de } \\
\text { pesquisa, assim como as } \\
\text { tendências e impactos } \\
\text { relacionados a pressupostos de } \\
\text { ordem cultural, geográfica ou } \\
\text { histórica e/ou atualidade da fonte } \\
\text { de informação. } \\
\text { 3.2.4 Demonstra a habilidade de } \\
\text { encontrar a informação sobre a } \\
\text { autoridade e qualificação de } \\
\text { autores e/ou editores-produtores. }\end{array}$ & $\begin{array}{l}\text { Cataloga e classifica } \\
\text { documentos e recurso } \\
\text { em geral }\end{array}$ & $\begin{array}{l}\text { Precisa saber como avaliar os documentos e } \\
\text { recursos e interpretar seu conteúdo textual a } \\
\text { fim de que a classificação seja eficaz, numa } \\
\text { linguagem acessível ao usuário. Necessita } \\
\text { avaliar a fonte de informação por meio da } \\
\text { pesquisa e verificar de que maneira seus } \\
\text { valores culturais influenciam no documento. } \\
\text { Deve saber como encontrar a informação sobe } \\
\text { os autores e editores a fim de realizar parcerias } \\
\text { futuras. }\end{array}$ \\
\hline $\begin{array}{l}\text { Padrão } 4 \text { - A pessoa "competente } \\
\text { em informação" utiliza a } \\
\text { informação com efetividade a fim } \\
\text { de alcançar um objetivo/resultado. }\end{array}$ & $\begin{array}{lrr}\text { Forma para } & \text { a } \\
\text { utilização } & & \text { da } \\
\text { biblioteca } & & \end{array}$ & $\begin{array}{l}\text { O profissional deve conhecer as razoes pelas } \\
\text { quais os usuários irão usar a informação, } \\
\text { podendo ser para lazer, tirar dúvidas, aprender, } \\
\text { ler e escrever, fazer um trabalho ou realizar a } \\
\text { tarefa da escola. }\end{array}$ \\
\hline $\begin{array}{l}\text { Padrão } 5 \text { - A pessoa "competente } \\
\text { em informação" compreende as } \\
\text { questões (econômicas, legais e }\end{array}$ & $\begin{array}{lr}\text { Forma } & \text { nas } \\
\text { competências } & \text { de } \\
\text { literacia } & \text { da } \\
\end{array}$ & $\begin{array}{l}\text { Seja competente em informação, valorize essa } \\
\text { competência e direcione suas ações para que os } \\
\text { usuários possam adquirir habilidades, }\end{array}$ \\
\hline RDBCl: Rev. Digit. Bibliotecon. Cienc. & \begin{tabular}{l|l|} 
nf. & Campinas, SP \\
\end{tabular} & \begin{tabular}{c|c|c|c|} 
v.17 & $1-23$ & e019005 & 2019 \\
\end{tabular} \\
\hline
\end{tabular}




\begin{tabular}{|c|c|c|}
\hline $\begin{array}{l}\text { sociais) que envolvem o uso da } \\
\text { informação, acessa e utiliza essa } \\
\text { informação de forma ética e legal. }\end{array}$ & $\begin{array}{lll}\text { informação e } & \text { de } \\
\text { conhecimento } & \text { da } \\
\text { informação } & \end{array}$ & $\begin{array}{l}\text { capacidades e experiências a partir do acesso a } \\
\text { informação. O principal objetivo da } \\
\text { Competência em informação é o de que os } \\
\text { indivíduos compreendam o contexto que vivem } \\
\text { e valorize a ética e a lei ao usar as informações. }\end{array}$ \\
\hline $\begin{array}{l}\text { 4.1.1 Organiza a informação, } \\
\text { utilizando esquemas ou estruturas } \\
\text { diversas. }\end{array}$ & $\begin{array}{lr}\text { Apoia alunos } & \text { e } \\
\text { professores } & \text { na } \\
\text { utilização de recursos } \\
\text { da biblioteca e } & \text { de } \\
\text { tecnologia } & \text { da } \\
\text { informação } & \end{array}$ & $\begin{array}{l}\text { Organizar as informações necessárias aos } \\
\text { professores e gestores que fazem parte da } \\
\text { equipe de modo que facilite sua recuperação } \\
\text { futura. Além disso, a organiza contribui para } \\
\text { que o profissional desenvolva os projetos da } \\
\text { biblioteca segundo as determinações da equipe } \\
\text { com base nos recursos que possui. }\end{array}$ \\
\hline $\begin{array}{l}\text { 5.2.4 Demonstra conhecimento do } \\
\text { que é o plágio e como não usá-lo } \\
\text { em suas comunicações. } \\
\text { 5.2.5 Obtém autorização para } \\
\text { realizar cópias de textos, imagens } \\
\text { e sons para incluir em seu produto } \\
\text { final. }\end{array}$ & $\begin{array}{l}\text { Dá resposta a pedidos } \\
\text { de referência e de } \\
\text { informação utilizando } \\
\text { os materiais } \\
\text { adequados }\end{array}$ & $\begin{array}{l}\text { Conhecer os documentos e recursos } \\
\text { disponíveis, dissemina as informações com os } \\
\text { usuários se atentando ao plagio, além disso } \\
\text { valoriza as propriedades intelectuais e as } \\
\text { respeitam em seus projetos. } \\
\text { Ensina o uso de fontes e aplicação de normas } \\
\text { na correta forma de citá-las }\end{array}$ \\
\hline $\begin{array}{l}\text { 5.1 Demonstra conhecimento } \\
\text { sobre questões éticas, sociais e } \\
\text { legais que envolvem informação, } \\
\text { comunicação e tecnologia. }\end{array}$ & $\begin{array}{l}\text { Promove programas } \\
\text { de leitura e eventos } \\
\text { culturais }\end{array}$ & $\begin{array}{l}\text { Criar eventos que una os usuários, professores } \\
\text { e os gestores dentro da escola a fim de que } \\
\text { todos os membros compreendam as questões } \\
\text { que envolvem o uso da ambiência da } \\
\text { informação, demonstrando a importância da } \\
\text { biblioteca e de seu papel. Esse tipo de iniciativa } \\
\text { contribui para evitar conflitos entre os } \\
\text { indivíduos e demonstrar a importância de se } \\
\text { conhecer a atuação de todos na educação dos } \\
\text { alunos. }\end{array}$ \\
\hline $\begin{array}{l}\text { 3.3.3 Compara a nova informação } \\
\text { com o conhecimento próprio e } \\
\text { outras fontes consideradas como } \\
\text { autoridade no assunto para } \\
\text { conclusões. }\end{array}$ & $\begin{array}{l}\text { Participa } \quad \text { de } \\
\text { atividades } \\
\text { planificação } \\
\text { relacionadas com a } \\
\text { gestão do curriculum }\end{array}$ & $\begin{array}{l}\text { Comunicar com os demais membros } \\
\text { organizacionais, atue na elaboração do } \\
\text { currículo demonstrando como a biblioteca pode } \\
\text { ajudar a atingir aos objetivos. Aprenda com o } \\
\text { conhecimento dos demais profissionais e } \\
\text { compare com o seu próprio. O bibliotecário } \\
\text { escolar também precisa apender em grupo. }\end{array}$ \\
\hline $\begin{array}{l}\text { 3.1.3 Identifica textualmente a } \\
\text { informação } \\
\text { adequadamente transcrita ou } \\
\text { parafraseada. } \\
\text { 3.2.1 Examina de forma } \\
\text { comparativa a informação de } \\
\text { diferentes fontes a fim de avaliar } \\
\text { sua confiabilidade, validade, } \\
\text { autoridade, precisão, atualidade, } \\
\text { ponto de vista e tendências. }\end{array}$ & $\begin{array}{l}\text { Participa na } \\
\text { preparação, } \\
\text { promoção e avaliação } \\
\text { de atividades de } \\
\text { aprendizagem }\end{array}$ & $\begin{array}{l}\text { Contribuir com os professores durante a criação } \\
\text { de um evento, atividade especifica. Ajudar os } \\
\text { professores a avaliar as atividades e identifique } \\
\text { plagio, o autor e as ideologia que influenciam a } \\
\text { fonte da informação obtida. }\end{array}$ \\
\hline $\begin{array}{l}\text { 2.4.1 Avalia a quantidade, } \\
\text { qualidade e relevância dos } \\
\text { resultados da pesquisa para } \\
\text { determinar sistemas alternativos } \\
\text { de recuperação da informação ou } \\
\text { métodos de pesquisa ainda } \\
\text { precisam ser usados. }\end{array}$ & $\begin{array}{l}\text { Promove a avaliação } \\
\text { de serviços de } \\
\text { biblioteca enquanto } \\
\text { componente normal e } \\
\text { regular do sistema de } \\
\text { avaliação global da } \\
\text { escola }\end{array}$ & $\begin{array}{l}\text { Avaliar os recursos e serviços por meio de } \\
\text { pesquisas com os usuários e, com isso, crie } \\
\text { outros modos de recuperar a informação } \\
\text { segundo as necessidades dos indivíduos. }\end{array}$ \\
\hline Padrão 4 - A pessoa "competente & Constrói parcerias & o trabalho \\
\hline RDBCl: Rev. Digit. Bibliotecon. Cienc & Campinas, SP & $\mathrm{e} 019005$ \\
\hline
\end{tabular}




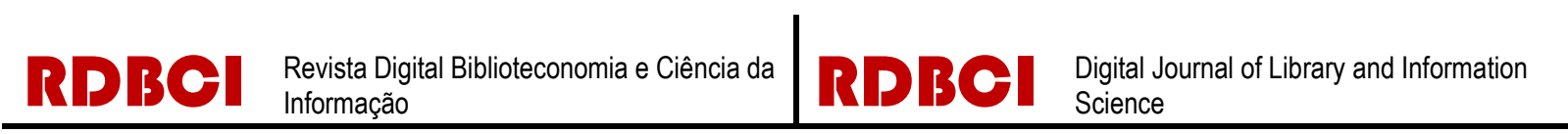

\begin{tabular}{|c|c|c|}
\hline $\begin{array}{l}\text { em informação" utiliza a } \\
\text { informação com efetividade a fim } \\
\text { de alcançar um objetivo/resultado. }\end{array}$ & $\begin{array}{l}\text { com organizações } \\
\text { externas }\end{array}$ & $\begin{array}{l}\text { possibilidade de coletar informações dos } \\
\text { colegas, não obstante, busque parcerias com } \\
\text { editoras, prefeituras, ONGs, empresas para } \\
\text { melhorar o arcabouço documental e oferecer } \\
\text { novos eventos }\end{array}$ \\
\hline $\begin{array}{l}1.2 \text { Identifica diferentes } \\
\text { tipos/formatos de fontes de } \\
\text { informação em potencial. } \\
1.3 \text { Avalia custos e benefícios } \\
\text { referentes a aquisição da } \\
\text { informação desejada. }\end{array}$ & $\begin{array}{l}\text { Prepara e aplica } \\
\text { orçamentos. Concebe } \\
\text { planeamento } \\
\text { estratégico }\end{array}$ & $\begin{array}{l}\text { Planejar o valor a ser gasto com os projetos e } \\
\text { maneiras de captação de recursos junto ao } \\
\text { Governo e a outras organizações. Avaliar o } \\
\text { custo da aquisição das informações necessárias } \\
\text { para o desenvolvimento do currículo e apoio a } \\
\text { aprendizagem ao longo da vida dos usuários. }\end{array}$ \\
\hline $\begin{array}{l}\text { 1.3.1 Determina a disponibilidade } \\
\text { da informação necessária e toma } \\
\text { decisões sobre as estratégias de } \\
\text { pesquisa da informação e o uso de } \\
\text { serviços de informação e qual a } \\
\text { mídia adequada (por exemplo: } \\
\text { intercâmbio, utilização de fontes } \\
\text { locais, obtenção de imagens, } \\
\text { vídeos, textos ou registros } \\
\text { sonoros, etc.). } \\
\text { 1.3.2 Determina um planejamento } \\
\text { exequível e um cronograma } \\
\text { adequado para a obtenção da } \\
\text { informação necessária. }\end{array}$ & $\begin{array}{l}\text { Faz a gestão e a } \\
\text { formação da equipe } \\
\text { da biblioteca }\end{array}$ & $\begin{array}{l}\text { Realizar a gestão dos documentos, recursos, } \\
\text { informações e decidir qual é a melhor estratégia } \\
\text { para atingir o objetivo proposto. Identificar } \\
\text { vários tipos de mídias a serem utilizadas e qual } \\
\text { é o mais rentável e está de acordo com as } \\
\text { necessidades dos usuários. Ajudar a equipe da } \\
\text { biblioteca, os professores e gestores a } \\
\text { implementar eventos e atividades extra } \\
\text { curriculares de aprendizagem. }\end{array}$ \\
\hline
\end{tabular}

Fonte: [os autores baseados em Belluzzo (2007) e Vitorino (2006)].

O bibliotecário escolar precisa ser competente em informação a fim de flexibilizar os recursos da biblioteca escolar com relação aos objetivos propostos pelos professores e gestores da escola. Em cada atividade, conta com padrões e indicadores de Competência em informação para atuar de modo inteligente e eficaz, respeitando o contexto cultural dos usuários.

Precisa conhecer a necessidade de informação dos usuários da comunidade escolar; estar em contato com os alunos e participar das aulas, palestras e eventos da escola; fazer parcerias com os demais membros da organização e participar da reuniões e desenvolvimento dos currículos. Essa etapa corresponde ao padrão 1 da Competência em informação: Padrão 1, quando "a pessoa competente em informação determina a natureza e a extensão da necessidade de informação" (BELLUZZO, 2007, p. 95), e corresponde à análise dos recursos e das necessidades de informação da comunidade escolar (VITORINO, 2006). Realiza a gestão dos documentos, recursos, informações e decide qual é a melhor estratégia para atingir o objetivo proposto. Identifica vários tipos de mídias a serem utilizadas e qual é o mais rentável e está de acordo com as necessidades dos usuários. Ajuda a equipe da biblioteca, os professores e gestores a implementar eventos e atividades extracurriculares de aprendizagem.

Nesse aspecto, quando as bibliotecas escolares elaboram práticas e ações de modo a assumir a responsabilidade do suporte pedagógico, a aprendizagem pode ocorrer de forma significativa e eficiente no sentido de fornecer a Competência em informação como

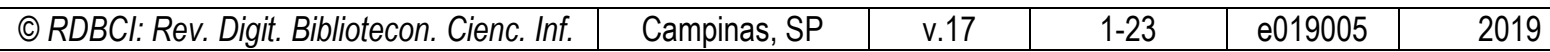


RDBCI

necessidade de busca, acesso e disseminação da informação na esfera da pesquisa escolar. $\mathrm{O}$ bibliotecário escolar deve formular e promover políticas para o desenvolvimento dos serviços juntamente com o Padrão 2, no qual "a pessoa competente em informação acessa a informação necessária com efetividade” (BELLUZZO, 2007, p. 97). Avalia os recursos e serviços por meio de pesquisas com os usuários e, com isso, crie outros modos de recuperar a informação segundo as necessidades dos indivíduos.

A biblioteca é tomada como um patrimônio científico e cultural, elemento disseminador da informação e formador de opinião que participa do desenvolvimento do cidadão, um espaço privilegiado de ação pedagógica. Neste sentido, políticas públicas são necessárias para o desenvolvimento de coleções, o planejamento de ações na escolha de fontes de informação e na busca de metodologias de acesso à informação, o fomento da leitura e o próprio avanço das bibliotecas escolares.

É preciso conhecer as formas com que os usuários podem acessar os recursos da biblioteca, as formas como são manuseadas as tecnologias de informação e comunicação, as formas como são emprestados livros, vídeos, revistas, desenvolvendo assim uma política institucional segundo os recursos e as necessidades dos usuários. Conforme explica Vitorino (2006), o profissional precisa desenvolver políticas e sistemas de aquisição para os recursos da biblioteca e o Padrão 3 explica que "a pessoa competente em informação avalia criticamente a informação e as suas fontes" (BELLUZZO, 2007, p. 99).

O bibliotecário escolar precisa saber como avaliar os documentos e recursos e interpretar seu conteúdo textual a fim de que a classificação seja eficaz, numa linguagem acessível ao usuário. Necessita avaliar a fonte de informação por meio da pesquisa e verificar de que maneira seus valores culturais influenciam no documento. Deve saber como ancorar a informação sobre os autores e editores a fim de realizar parcerias futuras. Aprende com o conhecimento dos demais profissionais e compara com o seu próprio. O bibliotecário também precisa trabalhar em equipe.

Equipamentos e recursos tecnológicos digitais são necessários para as bibliotecas escolares como instrumentos pedagógicos de acesso à informação e à conexão de redes de informação. Em novos tempos, as redes de bibliotecas escolares são capazes de encontrar novas maneiras de suprir as necessidades de seus leitores e de suas funções, adaptando políticas, objetivos e modos de intervenção às mudanças sociais e às exigências da nova cultura de informação.

A biblioteca escolar funciona como uma via de acesso para a comunidade docente e discente, ao permitir a transformação da informação em conhecimento. Nessa perspectiva, o bibliotecário escolar tem a competência de avaliar a confiabilidade dos recursos \begin{tabular}{c|c|c|c|c|r}
\hline C RDBCl: Rev. Digit. Bibliotecon. Cienc. Inf. & Campinas, SP & v.17 & $1-23$ & e019005 & 2019
\end{tabular} 


\section{RDBCI \\ Science}

informacionais e interpretar o conteúdo desses recursos, assumindo assim a função, a posição e a ação de mediador da informação. No âmbito das bibliotecas escolares, o bibliotecário deve possuir saberes que, alinhados a suas competências e habilidades (técnicas e tecnológicas), permitam a geração e o uso da informação.

O profissional deve conhecer as razões pelas quais os usuários irão usar a informação, podendo ser para lazer, tirar dúvidas, aprender, ler e escrever, fazer um trabalho ou realizar a tarefa da escola. O bibliotecário escolar deve educar o usuário para a utilização da biblioteca (VITORINO, 2006) por meio do Padrão 4: "a pessoa competente em informação, individualmente ou como membro de um grupo, usa a informação com efetividade para alcançar um objetivo/obter um resultado" conforme Belluzzo (2007, p. 101). Ele organiza as informações necessárias aos professores e gestores que fazem parte da equipe de modo que facilite sua recuperação futura. Além disso, a organiza contribui para que o profissional desenvolva os projetos da biblioteca segundo as determinações da equipe com base nos recursos que possui.

Castro Filho e Campos (2014, p. 23), concordam que a biblioteca escolar deve ser

[...] um laboratório de pesquisa, que se permite que formem leitores; um centro de fazer educativo; que seja um local de comunicação e de utilização de várias fontes de informação, seja no suporte físico, impresso ou virtual; de busca de questionamentos e soluções de problemas; que precisa ser ativa; de entretenimento; e que tem como missão o desenvolvimento e a formação dos cidadãos.

O bibliotecário escolar deve ser competente em informação, valorizando essa competência e direcionando suas ações para que os usuários possam adquirir habilidades, capacidades e experiências a partir do acesso à informação. $\mathrm{O}$ principal objetivo da Competência em informação é o de que os indivíduos compreendam o contexto em que vivem e valorizem a ética e a lei ao usar as informações. Tais ações se pautam no dever do profissional, que, segundo Vitorino (2006), forma nas competências e de conhecimento da informação. De acordo com o Padrão 5, "a pessoa competente em informação compreende as questões econômicas, legais e sociais da ambiência do uso da informação e acessa e usa a informação ética e legalmente" (BELLUZZO, 2007, p. 103).

Ressalta-se que o profissional deve adotar políticas de Competência em informação e ao mesmo tempo ser competente em informação. Cria eventos que une os usuários, professores e os gestores dentro da escola a fim de que todos os membros compreendam as questões que envolvem o uso da ambiência da informação, demonstrando a importância da biblioteca escolar e de seu papel. Esse tipo de iniciativa contribui para evitar conflitos entre os indivíduos e demonstrar a importância de se conhecer a atuação de todos na educação dos alunos. 


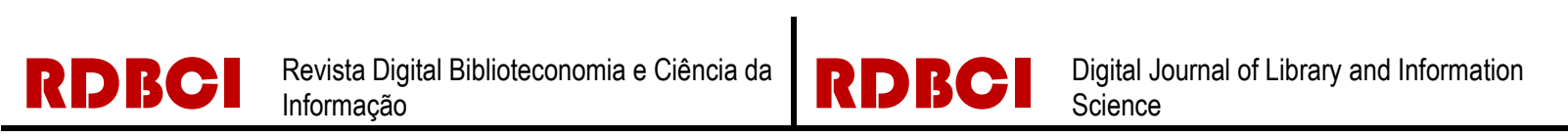

O bibliotecário escolar deve conhecer os documentos e os recursos disponíveis, disseminando as informações junto aos usuários, atentando ao plágio e valorizando as propriedades intelectuais. Portanto, é importante que a biblioteca escolar disponibilize um acervo que atenda aos interesses e às necessidades de docentes e discentes e, para isso, é necessário que os serviços da biblioteca escolar estejam integrados a um Projeto Político Pedagógico.

Numa sociedade onde o volume de informações aumenta a cada momento, é determinante saber interpretar e selecionar as informações. Instância introdutória para um projeto educativo de dimensões e alcances mais amplos, a biblioteca escolar afigura-se como a instituição responsável por estimular no indivíduo o lado crítico e questionador, característica marcante para o exercício consciente da cidadania, demarcando sua função social.

Invariavelmente os valores da relação entre biblioteca e sala de aula estão ausentes das discussões pedagógicas na escola. Esboçam-se planos para os conteúdos serem trabalhados, mas são raras as discussões que diretamente aproximam a biblioteca dos professores e dos coordenadores pedagógicos. O uso adequado da biblioteca é crucial para a realização de uma pesquisa satisfatória cujo hábito, incentivo e treinamento são elementos fundamentais para uma contribuição relevante em que o estudante possa encontrar, ou descobrir, as respostas às suas indagações e investigações, expandindo os horizontes de seus conhecimentos, formando uma visão de mundo crítica e assim se tornando um usuário competente e, sobretudo, um cidadão crítico.

\section{CONSIDERAÇõES FINAIS}

Observamos que há a necessidade de uma mediação da informação no contexto de competências em informação, que pode contribuir para as funções e ações da biblioteca escolar, não apenas como uma atribuição meramente pedagógica, mas também em vários aspectos que podem ser complementares, convergentes e/ou até divergentes: físico/digital; pedagógico/técnico; tecnológico/humano; ensino/pesquisa; docentes/discentes; tanto de forma individualizada quanto coletiva. Todos estes atributos refletem-se positivamente nos resultados das análises que utilizaram os padrões da Competência em informação trabalhados neste artigo.

O presente artigo demonstrou que a Competência em informação tem um potencial forte de contribuição com as políticas públicas da biblioteca escolar, pois é fundamental que a sociedade brasileira seja guiada pelo aprendizado ao longo da vida, inclusive o profissional da informação. Contudo, ainda existem poucos esforços em âmbito político e por isso, os 


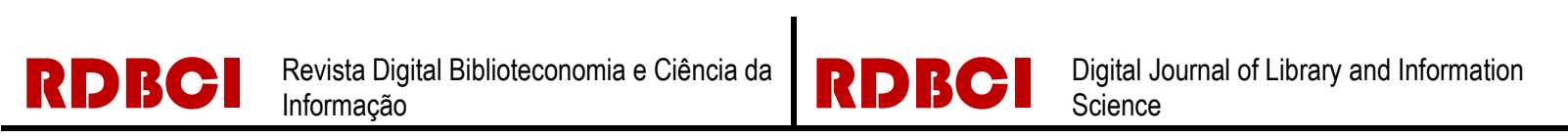

pesquisadores da área da Ciência da Informação vêm realizando congressos, palestras, pesquisas e participam da elaboração das políticas públicas de biblioteca.

O Projeto de Lei n. 212 (BRASIL, 2016) que institui a Política Nacional de Leitura e Escrita, firmado em 2017, se traduz como uma nova esperança rumo à Competência em informação no Brasil. Pela primeira vez, um projeto de política pública menciona o termo 'Competência em informação', tal fato demonstra que os esforços dos pesquisadores vêm sendo cada vez mais reconhecidos pela esfera governamental.

O trabalho desempenhado nas bibliotecas escolares brasileiras exige do bibliotecário muito mais do que habilidades técnicas (saber organizar e classificar os materiais do acervo); exige principalmente atributos sociais (colaboração/parceria entre bibliotecas; compartilhamento do conhecimento; trabalho em equipe; práticas de gestão do conhecimento e novos estilos na gestão das bibliotecas).

No âmbito das tecnologias de informação e comunicação, algumas escolas públicas têm laboratórios de multimídia praticamente separados das bibliotecas, por vezes funcionando apenas como meros anexos de salas de leitura, sem que se pense na possibilidade de uma interface entre eles, de modo que podemos perguntar: não seria o momento de capacitarmos profissionais, no sentido de realizar ações de inclusão entre biblioteca, tecnologia, sujeito e leitor? Uma das respostas possíveis é a promoção de uma política pública de biblioteca escolar em âmbito federal, que envolva o país como um todo, de maneira que possamos começar a entender as especificidades ambientais/culturais de cada região. Outra opção poderia ser a do trabalho em conjunto envolvendo as universidades, as instituições e as entidades de classe, as organizações não governamentais, os Ministérios (da Cultura e da Educação) e as bibliotecas escolares, a fim de fortalecer as pesquisas no âmbito da Competência em informação dos profissionais bibliotecários.

Nesse sentido, o bibliotecário escolar, em seu papel social, também deve ser sensível e proporcionar ambientes que contribuam para amenizar a carência do acesso à informação e a exclusão digital. Para tanto, pode-se realizar ações como: disponibilizar wi-fi na biblioteca e ofertar capacitações para a utilização das ferramentas de pesquisa. Ao contribuir para a inclusão digital e a Competência em informação, o bibliotecário assume uma postura política e social, que contribui para a formação integral do indivíduo na sociedade brasileira. 


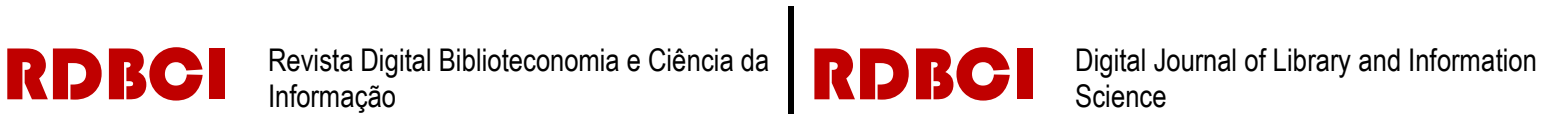

\section{REFERÊNCIAS}

BELLUZZO, R. C. B. Construção de mapas: desenvolvendo competências em informação e comunicação. Bauru: Cá Entre Nós, 2007.

BELLUZZO, R. C. B. O estado da arte da competência em informação no Brasil: das reflexões iniciais à apresentação e descrição de indicadores de análise. Revista Brasileira de Biblioteconomia e Documentação, São Paulo, v. 13, n. especial, p. 47-76, jan./jul. 2017.

BELLUZZO, R. C. B.; FERES, G. G. Competência em informação, redes de conhecimento e as metas educativas para 2021: reflexões e inter-relações. In: BELLUZZO, R. C. B; FERES, G. G.; VALENTIM, M. L. P. (Org.). Redes de conhecimento e competência em informação: interfaces da gestão, mediação e uso da informação/organização. Rio de Janeiro: Interciência, 2015, p.1-35.

BELLUZZO, R. C. B.; KOBAYASHI, M. C. M.; FERES, G. G. Information literacy: um indicador de competência para a formação permanente de professores na sociedade do conhecimento. ETD: Educação Temática Digital, Campinas, v. 6, n. 1, p. 81- 99, dez. 2004. Disponível em: https://www.fe.unicamp.br/revistas/ged/etd/article/view/2009/1837. Acesso em: 18 jul. 2017.

BRASIL. Decreto n. 7.559, setembro de 2011. Dispõe sobre o Plano Nacional do Livro e Leitura - PNLL e dá outras providências. Diário Oficial da União, Brasília, DF, 3 set. 2011. Seção I, p. 4.

BRASIL. Lei n. 10.753, outubro de 2003. Institui a Política Nacional do Livro. Diário Oficial da União, Brasília, DF, 31 out. 2003. Seção Extra, p.1.

BRASIL. Lei n. 12.244, maio de 2010. Dispõe sobre a universalização das bibliotecas nas instituições de ensino do País. Diário Oficial da União, Brasília, DF, 25 maio 2010. n. 98, Seção I, p. 3.

BRASIL. Lei n. 13.005, junho de 2014. Aprova o Plano Nacional de Educação - PNE e dá outras providências. Diário Oficial da União, Brasília, DF, 26 jun. 2014. Seção Extra, p. 1.

BRASIL. Portaria Ministerial n. 584, abril de 1997. Programa Nacional Biblioteca da Escola PNBE. Diário Oficial da União, Brasília, DF, 29 abr. 1997. Seção I, p. 8519.

BRASIL. Projeto de lei n. 212, maio de 2016. Institui a Política Nacional de Leitura e Escrita. Brasília, 2016.

BRASIL. Projeto de Lei n. 28, fevereiro de 2015. Dispõe sobre a Política Nacional de Bibliotecas. Brasília, 2015.

\begin{tabular}{l|c|c|c|c|r|}
\hline (c) RDBCl: Rev. Digit. Bibliotecon. Cienc. Inf. & Campinas, SP & v.17 & $1-23$ & e019005 & 2019 \\
\hline
\end{tabular}




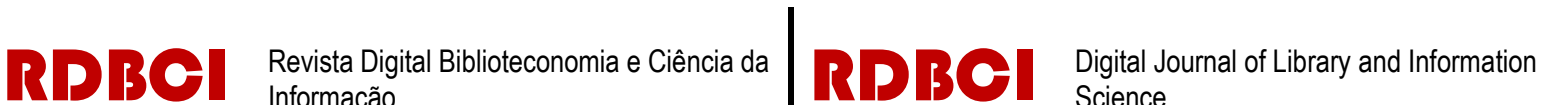

BRASIL. Lei 13.696, julho de 2018, que institui a Política Nacional de Leitura e Escrita. Brasília, 2016.

CAMPELLO, B. S. O movimento da competência informacional: uma perspectiva para o letramento informacional. Ciência da Informação, Brasília, v. 32, n. 3, p. 28-37, set./dez. 2003. Disponível em: http://revista.ibict.br/ciinf/index.php/ciinf/article/view/26/22. Acesso em: 18 jul. 2017.

CARTA de Marília. In: SEMINÁRIO DE COMPETÊNCIA EM INFORMAÇÃO: CENÁRIOS E TENDÊNCIAS, 3., 2014. Marília: Unesp, UnB, IBICT, 2014. Disponível em: http://www.valentim.pro.br/GICIO/Textos/Carta_de_Marilia_Portugues_Final.pdf. Acesso em: 31 jul. 2017.

CASTRO FILHO, C. M. Políticas públicas, biblioteca e as competências no contexto escolar. In: ALVES, F. M. M.; CORRÊA, E. C. D.; LUCAS, E. R. O. Competência informacional: políticas públicas, teoria e prática. Salvador, EDUFBA, 2016.

CASTRO FILHO, C. M.; CAMPOS, L. B. Fontes de informação em biblioteca escolar. São Paulo: Todas as Musas, 2014.

CRISPINO, A. Introdução ao estudo das políticas públicas: uma visão interdisciplinar e contextualizada. Rio de janeiro: FGV, 2016.

DECLARAÇÃO de Maceió sobre Competência em informação, assinada durante o I Seminário sobre Competência informacional, evento paralelo ao $24^{\circ}$ Congresso Brasileiro de Biblioteconomia, Documentação e Ciência da Informação, Maceió, Alagoas, Brasil, 09 de agosto de 2011. Apoio FEBAB. Disponível em:

http://www.fci.unb.br/phocadownload/declaracaomaceio.pdf. Acesso em: 25 jul. 2017.

DEMASSON, A.; PARTRIDGE, H.; BRUCE, C. Information literacy and the serious leisure participant: variation in the experience of using information to learn. Information Research, v. 21, n. 2, jun., 2016. Disponível em: http://www.informationr.net/ir/21-2/paper711.html\#. WX83_4jyvIU. Acesso em: 31 jul. 2017.

DUDZIAK, A. E.; FERREIRA, S. M. S. P.; FERRARI, A. C. Competência Informacional e Midiática: uma revisão dos principais marcos políticos expressos por declarações e documentos. Revista Brasileira de Biblioteconomia e Documentação, São Paulo, v. 13, n. especial, p. 213-253, jan./jul. 2017.

MANIFESTO de Florianópolis sobre a competência e as populações vulneráveis e minorias. Assinado durante o II Seminário sobre Competência em informação: cenários e tendências, evento paralelo ao $25^{\circ}$ Congresso Brasileiro de Biblioteconomia, Documentação e Ciência da Informação, Florianópolis, Brasil, 2013. Apoio FEBAB. Disponível em: http://competenciainformacional.blogspot.com.br/2013/11/manifesto-de-florianopolis-sobre.html. Acesso em: 25 jul. 2017.

\begin{tabular}{l|l|l|l|l|l|}
\hline (c) RDBCl: Rev. Digit. Bibliotecon. Cienc. Inf. & Campinas, SP & v.17 & $1-23$ & e019005 & 2019 \\
\hline
\end{tabular}


SÃO PAULO. Lei n. 5.301, setembro de 1986. Dispõe sobre obrigatoriedade da existência de local adequado para biblioteca nos prédios escolares estaduais. São Paulo, 1986.

UNESCO; IFLA. Manifesto sobre a biblioteca escolar, 2015. Disponível em:

http://www.unesco.org/webworld/libraries/manifestos/school_manifesto_es.html. Acesso em: 25 ago. 2017.

VITORINO, E. Manifesto sobre a biblioteca escolar. UNESCO, 2006. Disponível em: https://www.ifla.org/files/assets/school-libraries-resource-centers/publications/school-libraryguidelines/school-library-guidelines-pt.pdf. Acesso em: 02 ago. 2017. 